\title{
Morphometric Analysis of Bats (Chiroptera) in the Campus Area of the University of Bengkulu, Using Principal Component Analysis
}

\author{
Santi Nurul Kamilah ${ }^{1, *}$ Mahesha Rama ${ }^{2}$ Jarulis $^{1}$ \\ ${ }^{I}$ Department of Biology, Faculty of Mathematics and Natural Sciences, University of Bengkulu, Kandang Limun, \\ Bengkulu 38112, Indonesia \\ ${ }^{2}$ Undergraduate Student, Department of Biology, Faculty of Mathematics and Natural Sciences, University of \\ Bengkulu, Kandang Limun, Bengkulu 38112, Indonesia \\ *Corresponding author. Email: santi.nurul.kamilah@unib.ac.id
}

\begin{abstract}
Bats are the true flying mammals in the world. Morphological identification based upon morphometric characteristics will needed to determine the type of bat species, particularly the closely related species with the high level of morphological similarity. This study was aimed to determine the distinguishing characteristics between bat species found in the campus area of the University of Bengkulu. Bats were caught using mist net. The data of body morphometric measurement of each bat was analyzed using the software of MINITAB 18. As a result, there were four species, namely Cynopterus branchyotis, Cynopterus sphinx of the suborder Megachiroptera, Macroglossus sobrinus, and Rhinolophus stheno of the suborder Microchiroptera. The main distinguishing morphometric characteristics between species within genus were forearm length and tibia length. Based on the morphometric characteristic of all bat species found in this study, Cynopterus branchyotis and Cynopterus sphinx was found to be the most closely related with a Similarity Index of $77.99 \%$, while the Similarity Index between the species and Rhinolophus stheno was $28.87 \%$. Moreover, the lowest Similarity Index was obtained between the species and Macroglossus sobrinus of only $0.01 \%$.
\end{abstract}

Keywords: Chiroptera, morphometry, Minitab, PCA

\section{INTRODUCTION}

Bats are the only group of mammals capable of flight, they are a group of order Chiroptera. This animal belongs to the group of small mammals, aerial and feeds at night (nocturnal). According to the Checklist of the Mammals of Indonesia (2019), a total of 238 bat species is distributed in Indonesia. They are found from the west to the east of Indonesia. Several species are widely found in the mainland and the surrounding small islands, for example, Miniopterus schreibersi, Pipistrellus tenuis, Myotis muricola, and Myotis adversus. Some are endemic species, such as Mormopterus doridae which is endemic to Sumatra and Otomops formosus that is endemic to Java. In addition, Acerodon celebensis and Boneia bidens are endemic to Sulawesi, Dobsonia moluccensis is endemic to Maluku, while Dobsonia emersa, Pteropus pohlei, and Nyctimene cyclotis are endemic to Papua [1].

Chiroptera is divided into two suborders.
Suborder Megachiroptera is relatively larger than suborder Microchiroptera. Other typical features of Megachiroptera are highly developed in sense of sight and smell, herbivorous, simple snout and ear without additional ornament on nose and ear. Group of suborders Microchiroptera has relatively smaller body size, less developed sense of sight. However, they are a highly developed sense of hearing. This group uses a sonar system to navigate and detect potential prey. Some species of Microchiroptera are specialized in eating insects (insectivorous), others eat fish (piscivorous), or other small animals like frogs, snakes, and centipedes (carnivorous), and a few species eat blood (sanguinivorous) [2].

The study of morphology is needed to investigate the relationship between the shape and function of animal body parts which support their effort to adapt to the environment. This morphological adaptation is one of mechanisms to survive from an environmental stress. Morphological features which distinguish 
species of bats are body size, shape of nose, ear, tail, wings, eye, and dental formula. However, in some species, particularly those with close relationship, similarity is often found, hence quick identification is not possible to apply. Therefore, morphometric data are required to facilitate the identification process. The standard of body size measurement collected for morphometric data to be further use in the identification process of bat included body weight, forearm length, ear length, tail length, tibia length, and hindfoot length [3], [4], [5].

\section{MATERIALS AND METHODS}

This study was conducted from NovemberDecember 2019, located in the campus area of the University of Bengkulu. We used some mist nets to catch the bats, leather gloves, headlamp, flashlight, caliper, and pouch. The mist nets were installed at 5.30-11.00 pm and 04.00-06.00 am in several locations around the campus area of the University of Bengkulu. Each individual captured was photographed, measured for its morphometric characteristics, and identified as a species. The bats that have been measured were released back into the captured area. Parts of body measured for identification purpose referred to [3], [4], [5] which consisted of ear length (ER), forearm length (FA), tail length (T), tibia length (TIB), and hindfoot length (HF).

The data used were the result of the combined measurement of all species of male and female bats captured. Data of morphometric measurement results were further analyzed using the software MINITAB 18. Principal Component Analysis was applied to identify the distinguishing character among the genus of Chiroptera. Scatterplot analysis between species used to determine the distinguishing morphometric characteristic between species within the same genera.

\section{RESULTS AND DISCUSSION}

A total of four species of bats were found in the campus area of the University of Bengkulu. They are Cynopterus branchyotis, Cynopterus sphinx, and Macroglossus sobrinus. They are group of the suborder Megachiroptera, family Pteropodidae. While Rhinolophus stheno is a group of Microchiroptera, family Rhinolophidae.

Table 1. Morphometric characteristics and standard deviation of measurement in bats found in the campus area of the University of Bengkulu

\begin{tabular}{llccccc}
\hline \multirow{2}{*}{ No } & Species & \multicolumn{5}{c}{ Average Score of Morphometric Characteristics (mm) } \\
\cline { 3 - 6 } & & ER & FA & T & TIB & HF \\
& & $(\overline{x \pm \text { SD })}$ & $(\overline{x \pm \text { SD })}$ & $(\overline{x \pm \text { SD })}$ & $(\overline{x \pm \text { SD })}$ & $(\overline{x \pm \text { SD })}$ \\
\hline 1. & Cynopterus branchyotis & $14.80 \pm 1.24$ & $59.03 \pm 2.65$ & $9.10 \pm 1.32$ & $21.83 \pm 0.97$ & $11.27 \pm 0.74$ \\
2. & Cynopterus sphinx & $16.23 \pm 0.95$ & $68.60 \pm 0.66$ & $10.44 \pm 0.84$ & $25.88 \pm 1.05$ & $12.93 \pm 0.48$ \\
3. & Macroglossus sobrinus & $14.98 \pm 0.30$ & $45.61 \pm 0.70$ & $1.70 \pm 1.17$ & $16.57 \pm 1.63$ & $12.50 \pm 1.67$ \\
4. & Rhinolophus stheno & $16.49 \pm 0.40$ & $42.83 \pm 1.25$ & $19.70 \pm 0.55$ & $20.27 \pm 0.86$ & $10.74 \pm 0.60$ \\
\hline
\end{tabular}

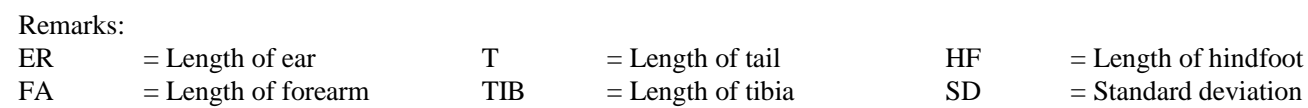

Based on morphometric measurements, it is known that each bat species has unique characteristics in size. Species $R$. stheno was found to have the largest ear (ER) and the longest tail (T) compared to other species. The long and wide ear, long tail which is completely covered by uropatagium membrane are important for this species to find and catch the prey. While, species C. sphinx had longer forearm (FA) and hindfoot (HF) compared to other species. The long and strong arm highly provide benefit to support the flying ability of this species. The long hindfoot really helps them to grip while roosting.

The principal component analysis based on eigenvalue resulted in cumulative value of principal component that reached $0.857(85.7 \%)$ for Principal Component 2 and $0.628(62.8 \%)$ for Principal Component 1. The data showed that combination of Principal Component 1 and 2 has been applied to distinguish the genus of bat. In Principal Component 1 , there were four characters which strongly distinguished between genus, namely ER, FA, TIB, and HF since all characters measured were found to contribute to differentiate the body shape of bat. In Principal Component 2, character with the highest contribution as the distinguishing characteristics between bats is tail length $(\mathrm{T})$. The cumulative value of the combination of Principal Component 1 and 2 represented $>75 \%$ of data. Therefore, both components were able to explain the Value of Total Diversity [6]. According to Budi [7] component with 
variance (eigenvalue) of greater than 1 has represented the structure of data, hence other

component with lower proportion of diversity might be considered not significant.

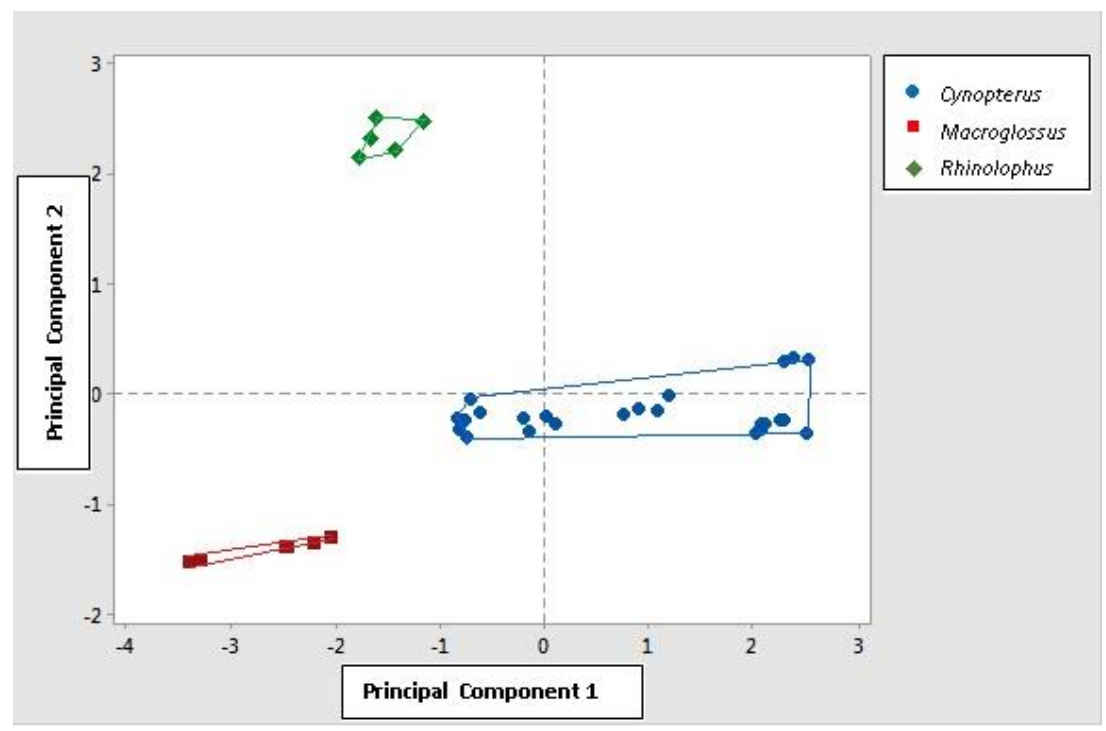

Figure 1. The graph of score plot of distinguishing characters between genus of bats found in the campus area of the University of Bengkulu according to the combination of Principal Component 1 and Principal Component 2

Visualization of the principal component analysis using the score plot graph (Figure 1) could illustrate the grouping of each individual of bat into the same genus. Based on Figure 1, each individual of bat was clustered according to their group, combination of Principal Component 1 and 2 indicated character similarity for each genus. In Principal Component 1, most individuals of the genus Cynopterus were in the right side of score plot, while all individuals of the genus Macroglossus and Rhinolophus were on the left side of score plot. Moreover, in Principal
Component 2. All individuals of the genus Cynopterus and Macroglossus were on the lower side, and all individuals of the genus Rhinolophus were on the upper part of score plot. Closeness between morphometric characteristics in all bat species is able to be investigated through biplot analysis of principal component (Figure 2). Biplot analysis is also used to examine the diversity of each character and the value of character variable to further determine the superiority of each character.

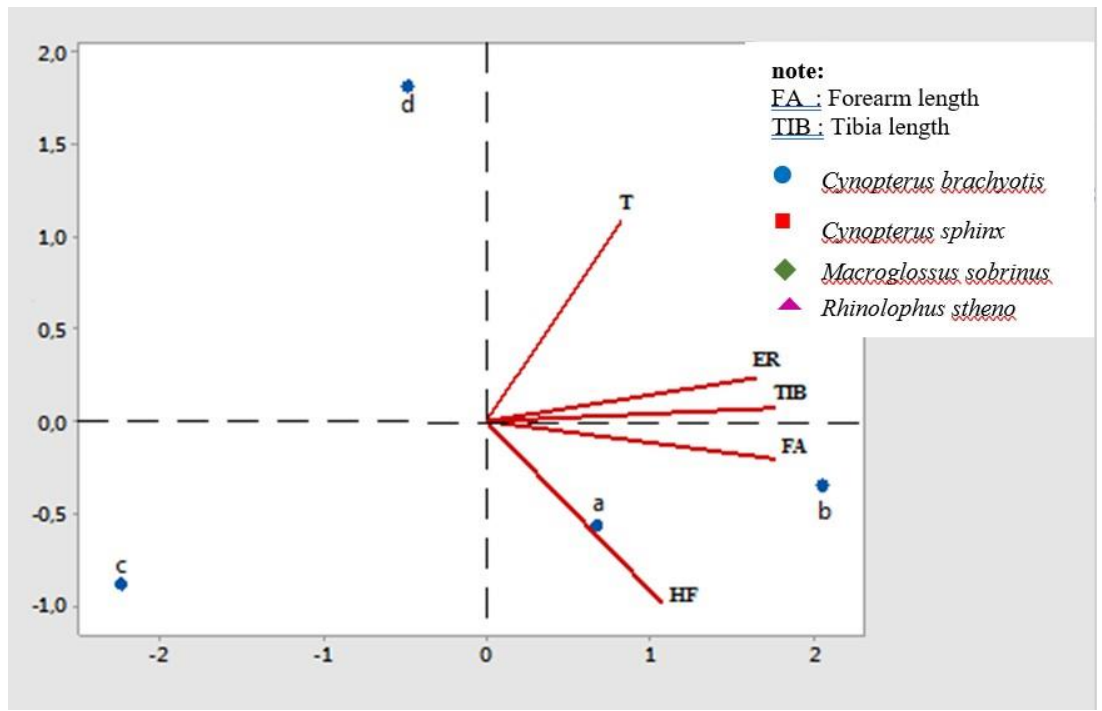

Figure 2. Biplot graph between morphometric characteristics of bats found in the campus area of the University of Bengkulu $(\mathrm{a}=C$. branchyotis, $\mathrm{b}=C$. sphinx, $\mathrm{c}=M$. sobrinus, $\mathrm{d}=R$. Stheno $)$ 
Based on Figure 2, the character of tail length (T), ear length (ER), tibia length (TIB), and forearm length (FA) were positively correlated in accordance with the less-than $90^{\circ}$ angles formed between characters, thus increase in one character will lead to increase in other character. The value of diversity is reflected by the red line where longer line indicates higher diversity. The character of tail length (T) and hindfoot length (HF) obtained extremely low diversity, that was close to zero. This indicates that the character value of each species was almost similar, yet other morphometric characteristics resulted in higher diversity.

Species M. sobrinus was found to have smaller size compared to species $R$. stheno and Cynopterus. This is related to the angle formed between a species and its morphometric characteristic. According to
Overton et al. (1997) [8], if the angle formed is greater than $90^{\circ}$, the body size of species will be above the average size of morphometric, while, if the formed angle is less than $90^{\circ}$ then the body size of the species is below the morphometric average size.

Morphometric characteristic between species was analyzed by scatter plot analysis. Scatter plot illustrates the relationship possibility (correlation) between a pair of two variables besides showing relationship closeness between the two variables, normally expressed as the coefficient of correlation [9]. Visualization of measurement between bat species through the distribution of individual value for each character was done to obtain the distribution of data between bat species as depicted in Figure 3 below.

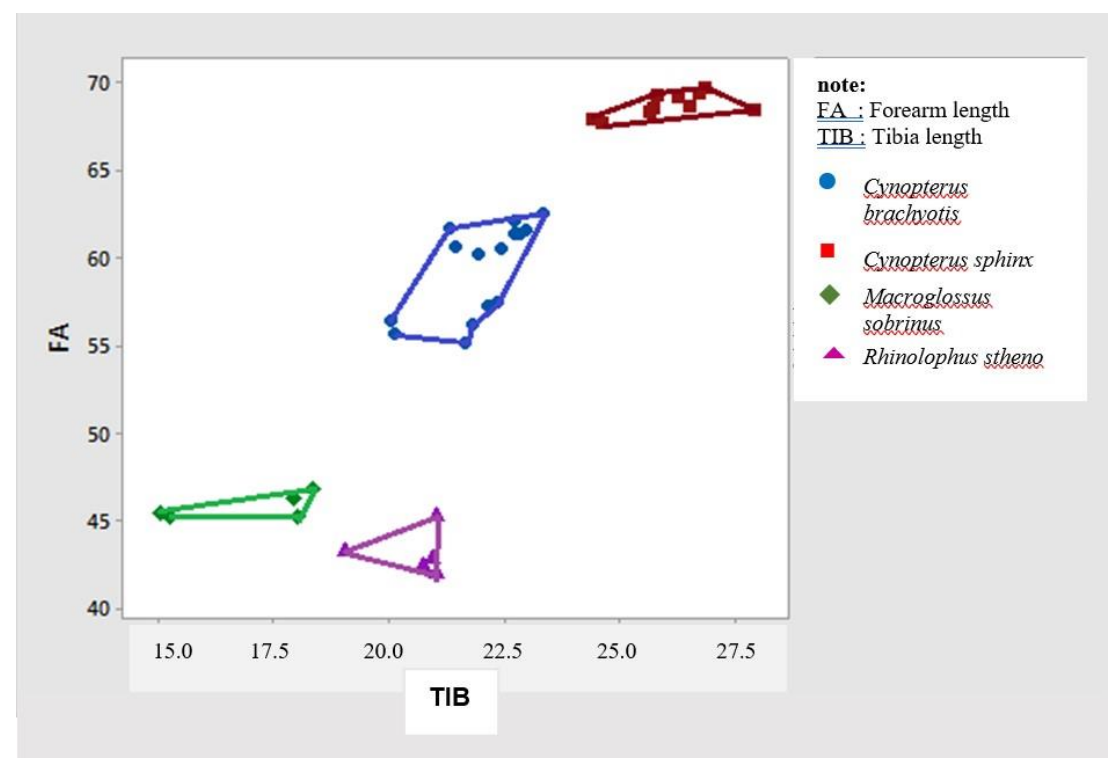

Figure 3. Scatterplot of combined FA and TIB characters of four bat species found in the campus area of the University of Bengkulu

Figure 3 depicts that combination of the character of forearm length (FA) and tibia length (TIB) was able to consistently separate individual of four bat species. Character of FA has united individual of species $C$. sphinx and $C$. branchyotis in group with FA range of 55.0-70.0 mm. Furthermore, species Macroglossus sobrinus and Rhinolophus stheno were included in lower group with FA range of 42.8-46.5 $\mathrm{mm}$. Later, TIB character separated individual of species $C$. sphinx and C. Branchyotis into group to the right side of scatter plot with size range of 20.0$28.0 \mathrm{~mm}$. Moreover, species $M$. sobrinus and $R$. stheno were on the left side of scatter plot with size range of 15,0-21.5 mm. Based on the result of the two characteristics, it is concluded that FA TIB were the distinguishing characters between species Chiroptera.

Result of scatter plot analysis on four bat species showed that species $C$. branchyotis and $C$. sphinx have genetic relationship based on morphometric characteristic. However, further scatter plot analysis according to the combination of morphometric characteristics of all individuals is necessary to determine the distinguishing characters between species. 


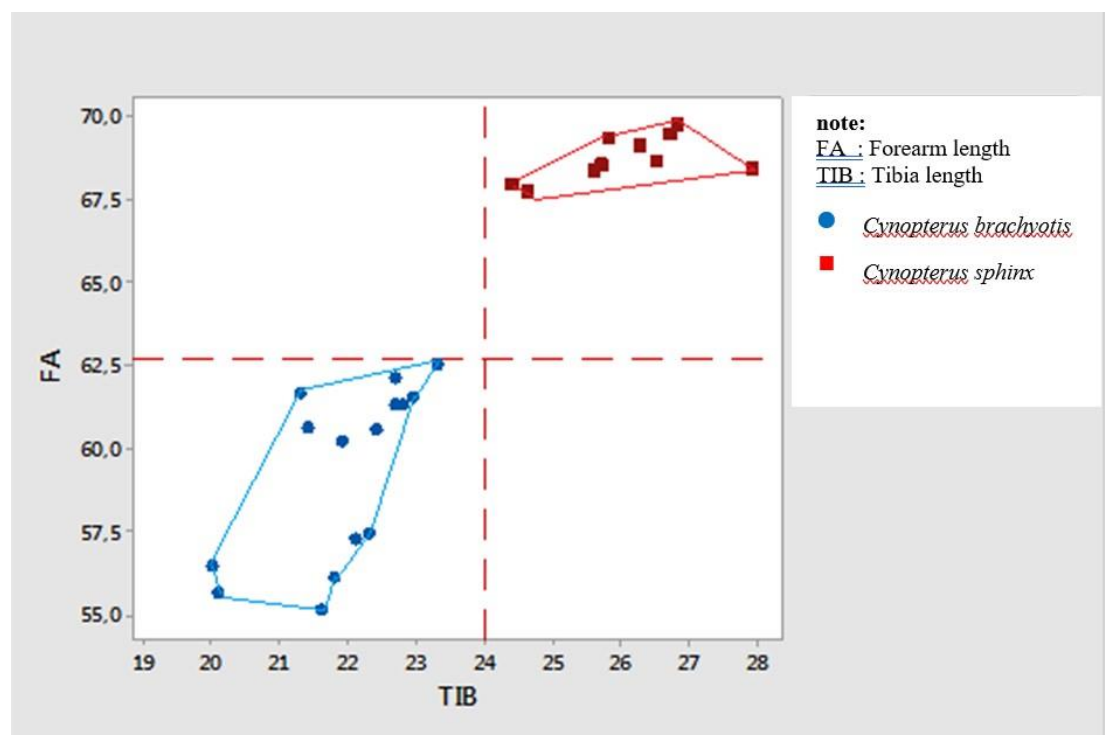

Figure 4. Scatterplot of combined FA and TIB characters of bat species within the same genus found in the campus area of the University of Bengkulu

As seen in Figure 4, character of forearm length (FA) and tibia length (TIB) could consistently separate the two individual species. Character of FA grouped individual of species $C$. sphinx into the upper group at size range of 67.5-70.0 $\mathrm{mm}$. Moreover, FA size of species $C$. branchyotis was included in lower group ranged of 55.0-62.5 mm. Later, TIB character has separated individual of species $C$. sphinx to the right side of scatter plot with size range of 24-28 $\mathrm{mm}$ and species $C$. branchyotis was plotted to the left side of scatter plot at size range of 20.0-23.5 mm. Based on the combination result of the two characters, it was found that characters of FA and TIB were the distinguishing characters between the genus Cynopterus. Analysis of genetic relationship applied in this study is multivariate technic with main objective to group objects/cases according to their characteristics. This analysis genetic relationship is classifying object, thus each object with similar characteristic (closely similar) will gather into one single group (cluster).

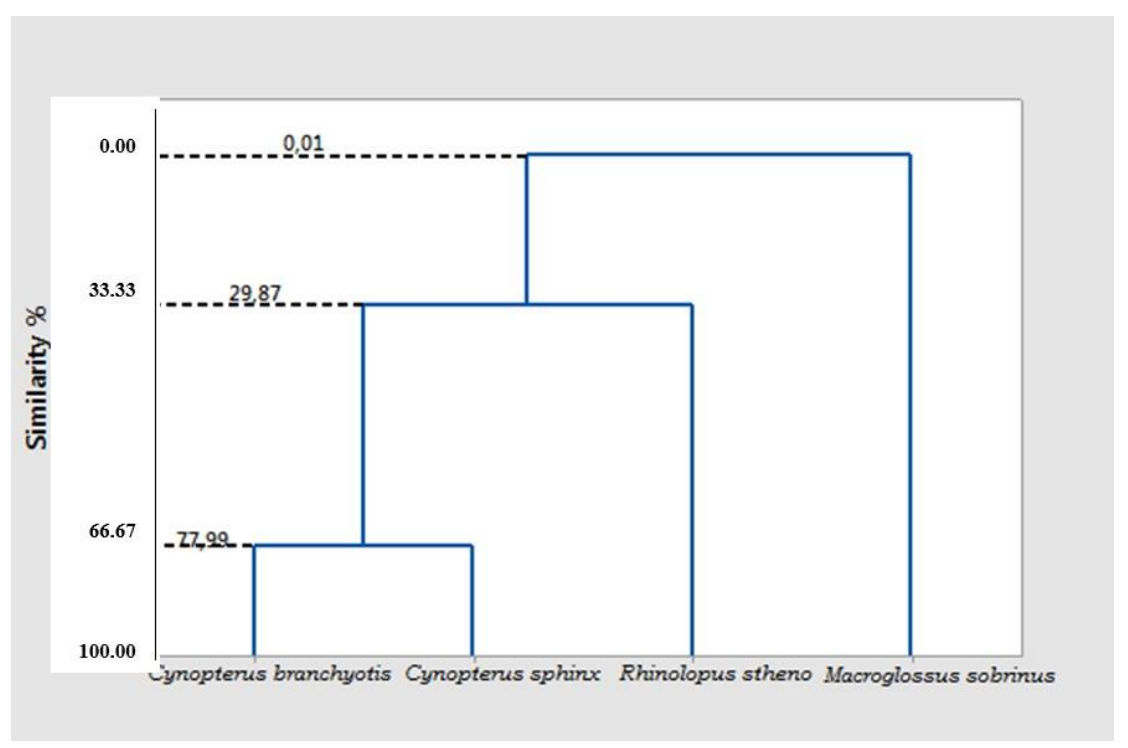

Figure 5. Genetic relationship of bat species found in the campus area of the University of Bengkulu by morphometric characteristics using euclidean model

Genetic relationship analysis between bat species showed that Cynopterus branchyotis was found to be most closely related to Cynopterus sphinx with
Similarity Index of $77.99 \%$. Both species obtained three similarities of morphometric characteristics, namely length of ear (ER), length of tail (T), and 
length of hindfoot (HF). However, the lowest Similarity Index of $0.01 \%$ was obtained between Macroglossus sobrinus and Rhinolophus stheno, Cynopterus branchyotis, and Cynopterus sphinx. Species $M$. sobrinus only had one similar morphometric characteristic to other species, i.e., the length of hindfoot (HF).

Based on Figure 6, it is seen that Cynopterus branchyotis and Cynopterus sphinx is closely related based on their morphometric characteristics. Study of Kamilah (2005) [10] found that both species has many similarities according to the morphometric characteristics. However, forearm length of C. Sphinx was found to be longer than that of $C$. branchyotis. If the four species are compared, it is easier to distinguish them by comparing the length of forearm and tail. Species $M$. sobrinus has a short tail length, while tail length of species $R$. stheno was the longest among all.

\section{CONCLUSION}

There are four species of bats found in the campus area of the University of Bengkulu. They are Cynopterus branchyotis, Cynopterus sphinx, and Macroglossus sobrinus, a group of the suborder Megachiroptera. The other species is Rhinolophus stheno that belongs to the suborder of Microchiroptera. The Morphometric characteristic that strongly distinguished the four species of bats was the combination of forearm length (FA) and tibia length (TIB). Moreover, Cynopterus branchyotis and Cynopterus sphinx were found to be most closely related with a Similarity Index of $77.99 \%$.

\section{ACKNOWLEDGMENT}

The authors would like to thank Haidar, Riko, Adiguna, and all parties for the support given throughout the completion of this research.

\section{REFERENCES}

[1] I. Maryanto, Maharadatunkamsi, S.A. Achmadi, S. Wiantoro, E. Sulistyadi, M. Yoneda, A. Suyanto, J. Sugardjito, Checklist of the mammals of Indonesia: Scientific, English, Indonesia name and distribution area table in Indonesia including CITES, IUCN and Indonesian Category for Conservation, Research Center for Biology, Indonesian Institute of Sciences (LIPI), 2019.

[2] R.M. Nowak, Walker's Mammals of the world. John Hopkins University Press, Baltimore and London, 1997.
[3] G.B. Corbet, J.E. Hill, The mammal of the Indomalayan region; A systematic review, Oxford University Press, 1992.

[4] J. Payne, C.M. Francis, K. Philipps, S.N. Kartikasari, Panduan lapangan mamalia di Kalimantan, Sabah, Serawak, dan Brunai Darussalam, The Sabah Society dan WWF, Kuala Lumpur, 2000. [In Bahasa Indonesia]

[5] A. Suyanto, Kelelawar di Indonesia: Seri Panduan Lapangan, Pusat Penelitian dan Pengembangan Biologi-LIPI, Bogor, 2001. [In Bahasa Indonesia]

[6] I. Djakaria, S. Guritno, S.H. Kartiko, Visualisasi data iris menggunakan Analisis Komponen Utama dan Analisis Komponen Utama Kernel, Jurnal Ilmu Dasar Vol. 11(1) (2010) 21-38. ([In Bahasa Indonesia]

[7] R. Budi, Bioacoustics of bat Sub Microchiroptera order in Seplawan Cave, Jurnal Prodi Biologi, 7 (3) (2018) 190-195

[8] J.L. Overton, D.J. Macintosh, R.S. Thorpe, Multivariate analysis of the mud crab Scylla serrata (Brachyura: Portunidae) from four locations in Southeast Asia, Marine Biology, 128(1) (1997) 55-62

[9] D. Coleman, Lean Sigma Corporation is a Trademark and DBA of LLC, hhtp://leansigmacorporation.com scatterplotwith-minitab// 2015 (accessed March 10 ${ }^{\text {th }} 2021$ )

[10] S.N. Kamilah, Diversitas Chiroptera pada habitat rawa dan perbukitan di Cagar Alam Rimbo Pati Pasaman, Tesis, Pascasarjana Biologi Universitas Andalas, Padang, 2005. [In Bahasa Indonesia] 